\title{
Pharmacological Characterization of IW-1973, a Novel Soluble Guanylate Cyclase Stimulator with Extensive Tissue Distribution, Antihypertensive, Anti-Inflammatory, and Antifibrotic Effects in Preclinical Models of Disease ${ }^{\mathbf{S}}$
}

\author{
Jenny V. Tobin, ${ }^{1}$ Daniel P. Zimmer, ${ }^{1}$ Courtney Shea, Peter Germano, Sylvie G. Bernier, \\ Guang Liu, Kim Long, Joy Miyashiro, Sheila Ranganath, Sarah Jacobson, Kim Tang, \\ G-Yoon Jamie Im, James Sheppeck, II, Joel D. Moore, Kristine Sykes, James Wakefield, \\ Renee Sarno, Ali R. Banijamali, Albert T. Profy, G. Todd Milne, Mark G. Currie, \\ and Jaime L. Masferrer
}

Ironwood Pharmaceuticals, Cambridge, Massachusetts

Received December 21, 2017; accepted March 20, 2018

\section{ABSTRACT}

Soluble guanylate cyclase (sGC), a key signal-transduction enzyme, increases the conversion of guanosine-5'-triphosphate to cGMP upon binding of nitric oxide (NO). Endothelial dysfunction and/or reduced NO signaling have been implicated in cardiovascular disease pathogenesis and complications of diabetes and have been associated with other disease states and aging. Soluble guanylate cyclase (sGC) stimulators are small-molecule drugs that bind SGC and enhance NO-mediated cGMP signaling. The pharmacological characterization of IW-1973 [1,1,1,3,3,3hexafluoro-2-(((5-fluoro-2-(1-(2-fluorobenzyl)-5-(isoxazol-3-yl)$1 H$-pyrazol-3-yl) pyrimidin-4-yl)amino)methyl)propan-2-ol], a novel clinical-stage sGC stimulator under clinical investigation for treatment of heart failure with preserved ejection fraction and diabetic nephropathy, is described. In the presence of NO, IW1973 stimulated sGC in a human purified enzyme assay and a HEK-293 whole cell assay. SGC stimulation by IW-1973 in cells was associated with increased phosphorylation of vasodilator-stimulated phosphoprotein. IW-1973, at doses of $1-10 \mathrm{mg} / \mathrm{kg}$, significantly lowered blood pressure in normotensive and spontaneously hypertensive rats. In a Dahl salt-sensitive hypertension model, IW-1973 significantly reduced blood pressure, inflammatory cytokine levels, and renal disease markers, including proteinuria and renal fibrotic gene expression. The results were affirmed in mouse lipopolysaccharide-induced inflammation and rat unilateral ureteral obstruction renal fibrosis models. A quantitative whole-body autoradiography study of IW-1973 revealed extensive tissue distribution and pharmacokinetic studies showed a large volume of distribution and a profile consistent with predicted once-a-day dosing in humans. In summary, IW-1973 is a potent, orally available sGC stimulator that exhibits renoprotective, anti-inflammatory, and antifibrotic effects in nonclinical models.

\section{Introduction}

Soluble guanylate cyclase (sGC) is the major receptor for nitric oxide (NO) and a key signal-transduction enzyme in the NO-cGMP signaling pathway. NO is a transient, locally acting signaling molecule that binds to the heme prosthetic group of sGC to induce a conformational change, resulting in the conversion of guanosine-5'-triphosphate to cGMP. cGMP in

\footnotetext{
${ }^{1}$ J.V.T. and D.P.Z. contributed equally to this work.

https://doi.org/10.1124/jpet.117.247429.

S This article has supplemental material available at jpet.aspetjournals.org
}

turn binds to and modulates the activity of downstream targets including protein kinase $G$, cyclic nucleotide-gated ion channels, and phosphodiesterases (PDEs) (Derbyshire and Marletta, 2012).

sGC is expressed in many cells and tissues (Budworth et al., 1999), but its role in vascular smooth muscle is the best understood. In response to vascular shear stress, endothelial NO synthase produces NO, which activates sGC present in neighboring vascular smooth muscle cells (Moncada and Higgs, 2006). This results in vasodilation and a concomitant increase in local blood flow (Moncada and Higgs, 2006). Several risk factors (e.g., age and smoking) and disease states

ABBREVIATIONS: ANOVA, analysis of variance; $\mathrm{Cl}$, confidence interval; DETA-NONOate, diethylenetriamine NONOate; DSS, Dahl salt sensitive; HBSS, Hanks' balanced salt solution; HR, heart rate; HS, high salt; HTRF, homogeneous time-resolved fluorescence; IBMX, 3-isobutyl-1methylxanthine; IL-6, interleukin 6; IW-1973, 1,1,1,3,3,3-hexafluoro-2-((5-fluoro-2-(1-(2-fluorobenzyl)-5-(isoxazol-3-yl)-1H-pyrazol-3-yl) pyrimidin4-yl)amino)methyl)propan-2-ol; LPS, lipopolysaccharide; MAP, mean arterial pressure; NO, nitric oxide; NS, normal salt; PDE, phosphodiesterase; PK, pharmacokinetic; pVASP, phosphorylated vasodilator-stimulated phosphoprotein; secondGC, second guanylate cyclase; sGC, soluble guanylate cyclase; SHR, spontaneously hypertensive rat; UUO, unilateral ureteral obstruction; VASP, vasodilator-stimulated phosphoprotein. 
(e.g., diabetes, heart failure, hypertension, and pulmonary hypertension) are associated with impaired NO signaling and endothelial dysfunction (Münzel et al., 2008). These associations as well as genetic studies of the NO-sGC-cGMP pathway suggest that long-term reduction in NO-sGC-cGMP signaling may contribute to hypertension; shortness-of-breath symptoms in heart failure and pulmonary hypertension; diabetic complications including nephropathy; and increased incidence of myocardial infarction, stroke, and death. A pharmacologic mechanism that enhances NO signaling and elevates cGMP levels may restore endothelial function and improve the course of disease.

The NO-sGC-cGMP pathway has a long history as a pharmacologic target beginning with the discovery of the NO donor nitroglycerin as a treatment of angina pectoris in the late 1800s (Murrell, 1879). NO released from donors such as nitroglycerin activate sGC, but do not preserve the precise spatiotemporal control of endogenous NO signaling. Although NO donors are potent vasodilators, tolerance to these agents readily develops. In the $1990 \mathrm{~s}$, the first inhibitors of the cGMP phosphodiesterase PDE5, which prevent cGMP breakdown, were approved for the treatment of erectile dysfunction, and later for the treatment of pulmonary arterial hypertension (Hrometz and Shields, 2006). However, endogenous cGMP production is a prerequisite for their pharmacological action, and PDE5 inhibitors are not specific to the sGC pathway because PDE5 modulates cGMP levels not only in cells containing sGC but also in cells containing the particulate guanylate cyclases. Indeed, the PDE5 inhibitor sildenafil was shown to augment vasodilatory activity of cGMP pools generated by particulate guanylate cylcases (Baliga et al., 2008).

sGC stimulators provide a new approach to modulating the NO-sGC-cGMP pathway by directly binding to sGC to enhance NO signaling. sGC stimulators are heme dependent, and importantly act in synergy with NO to increase cGMP production (Follmann et al., 2013). In this way, sGC stimulators preserve spatiotemporal control of endogenous NO signaling. The mechanism of action of sGC stimulators contrasts with sGC activators, which are heme independent and do not act in synergy with NO to increase cGMP (Follmann et al., 2013). sGC activators indiscriminately activate sGC and do not enhance endogenous NO signaling. To date, the clinical development of sGC activators has been limited by unacceptable hypotension (Erdmann et al., 2013).

The first sGC stimulator described was YC-1, a compound shown to increase platelet cGMP in vitro (Ko et al., 1994). More recently, newer sGC stimulators with improved pharmacologic properties have demonstrated efficacy in many preclinical disease models, including models of systemic and pulmonary hypertension, heart failure, nephropathy, and fibrotic diseases (Stasch et al., 2011, 2015; Gheorghiade et al., 2013; Glynos et al., 2015; Sandner and Stasch, 2017). In addition, sGC stimulators have demonstrated anti-inflammatory (Glynos et al., 2015), antifibrotic (Sandner and Stasch, 2017), and beneficial metabolic effects (Hoffmann et al., 2015a) in preclinical models. The sGC stimulator riociguat is approved in several countries for the treatment of pulmonary arterial hypertension and chronic thromboembolic pulmonary hypertension (Conole and Scott, 2013). There is increasing understanding of the extensive physiologic role of NO-sGC-cGMP signaling, and likewise a growing appreciation of the multidimensional pharmacology of sGC stimulators.
Based on the broad therapeutic potential of sGC stimulation, a medicinal chemistry effort was conducted to synthesize and characterize novel sGC stimulators with suitable pharmacological, pharmacokinetic (PK), and pharmaceutical properties for clinical investigation. Herein, we describe the pharmacology of IW-1973 [1,1,1,3,3,3-hexafluoro-2-(((5-fluoro2-(1-(2-fluorobenzyl)-5-(isoxazol-3-yl)-1H-pyrazol-3-yl) pyrimidin-4-yl)amino)methyl)propan-2-ol], a novel sGC stimulator in clinical development with potential as a treatment of a broad range of diseases.

\section{Materials and Methods}

Compounds. IW-1973 was synthesized at Ironwood Pharmaceuticals. Losartan (losartan potassium) was purchased from Tecoland Corporation (Irvine, CA). Dexamethasone was purchased from SigmaAldrich (St. Louis, MO).

Animals. All animals used in the studies were housed in Association for Assessment and Accreditation of Laboratory Animal Care-accredited animal facilities; all animal-use protocols were reviewed and approved by the Institutional Animal Care and Use Committee prior to commencement.

For the mouse study, animals were housed under controlled conditions (temperature $71.6-77^{\circ} \mathrm{F}$, relative humidity $30 \%-70 \%$ ) and exposed to a 12-hour light-dark cycle. All animals were acclimated to the facility for 7 days prior to study start and allowed free access to water and standard rodent chow.

For rat studies, all animals were housed under controlled conditions (temperature $72 \pm 8^{\circ} \mathrm{F}$ and relative humidity $30 \%-70 \%$ ) and exposed to a 12-hour light-dark cycle (6 AM to $6 \mathrm{PM}$ ). All animals were allowed free access to water and standard rodent chow (PicoLab Rodent Diet 20, LabDiet, St.Louis MO)) or special chow. All animals were acclimated to the facility for at least 2 to 3 days prior to study.

Human Tissues. Human subcutaneous resistance arteries for use in experiments studying human vascular tissue relaxation were obtained with proper authorization and full ethical approval from three donors (ReproCELL Europe Ltd., Beltsville, MD).

Formulations. Various formulations were employed to study both the acute and chronic effects of IW-1973 in a range of animal models. Formulations were chosen for suitability to a particular dosing regimen and animal model. IW-1973 formulation for each assay is described subsequently. Experimental outcomes were benchmarked using the plasma exposure of IW-1973 to make comparisons across studies.

sGC Enzyme Assay. Purified human recombinant $\alpha 1 \beta 1$ sGC was purchased from Enzo Life Sciences (Farmingdale, NY). A solution containing $12.5 \mathrm{ng} / \mathrm{ml}$ human $\mathrm{sGC}, 30 \mu \mathrm{M}$ diethylenetriamine NONOate (DETA-NONOate) (Enzo Life Sciences), $100 \mathrm{mM}$ Tris (pH 7.4), $4 \mathrm{mM} \mathrm{MgCl}$, $2 \mathrm{mM}$ dithiothreitol, and $0.05 \%$ bovine serum albumin was allowed to equilibrate to $37^{\circ} \mathrm{C}$ for 10 minutes in a prewarmed assay plate. For each test concentration, IW-1973 was diluted in dimethylsulfoxide to $33.3 \times$ its assay concentration, and then added to the assay plate. In some experiments, Tween 20 or $1 \mathrm{H}-[1,2,4]-$ oxadiazolo[4,3,-a]quinoxalin-1-one was added to this stock. Removal of the heme group by the nonionic detergent Tween-20 is known to render sGC insensitive to activation by NO and heme-dependent sGC stimulators, while leaving basal enzyme activity intact (Stasch et al., 2002). Guanosine-5'-triphosphate was added to the assay plate to a final concentration of $300 \mu \mathrm{M}$. Assay plates were incubated at $37^{\circ} \mathrm{C}$ for 20 minutes with shaking. The enzyme reaction was stopped with an equal volume of ice-cold $20 \%$ acetic acid. cGMP concentrations were determined using cGMP homogeneous time-resolved fluorescence (HTRF) (Cisbio, Bedford, MA) per the manufacturer's instructions.

A cGMP standard curve was fit using a four-parameter equation [log(inhibitor) vs. response - variable slope] with a 95\% confidence interval (CI) using GraphPad Prism software version 6 (Graphpad Software, San Diego, CA). Samples were diluted appropriately to 
ensure that all values fell within the linear range of the standard curve. Concentration response data were fit using a four-parameter fit [log(agonist) vs. response - variable slope] and GraphPad Prism version 6 . The $\mathrm{EC}_{50}$, defined as the concentration at which IW-1973 elicits $50 \%$ of its maximal response, was interpolated from the curve fit.

sGC Whole Cell Assay. HEK-293 cells (ATCC, Manassas, VA) were grown and maintained in Dulbecco's modified Eagle's medium containing $10 \%$ fetal bovine serum, $100 \mathrm{U} / \mathrm{ml}$ penicillin, and $100 \mu \mathrm{g} / \mathrm{ml}$ streptomycin. For sGC activity assays, cells were seeded in 384-well poly-D-lysine-coated flat-bottom plates (Fisher Scientific, Pittsburgh, PA) in $50 \mu \mathrm{l}$ medium at a density of $1.5 \times 10^{4}$ cells/well. Cells were incubated for 24 hours at $37^{\circ} \mathrm{C}$ in a humidified chamber supplemented with $5 \% \mathrm{CO}_{2}$. Medium was removed, and cells were washed once with $40 \mu \mathrm{l}$ of Hanks' balanced salt solution (HBSS) with calcium and magnesium. Cells were then incubated with $40 \mu \mathrm{l}$ of a solution containing $0.5 \mathrm{mM}$ 3-isobutyl-1-methylxanthine (IBMX) in HBSS with calcium and magnesium for 15 minutes at $37^{\circ} \mathrm{C}$. Then, $10 \mu \mathrm{l}$ of $5 \times$ the indicated final concentration of IW-1973 (diluted from a $10 \mathrm{mM}$ dimethylsulfoxide stock) with or without DETA-NONOate was added to the cells, which were then incubated for 20 minutes at $37^{\circ} \mathrm{C}$. Assay buffer was then removed and $50 \mu \mathrm{l}$ of ice-cold $10 \%$ acetic acid + $150 \mathrm{ng} / \mathrm{ml}$ internal standard cyclic ${ }^{13,15} \mathrm{~N}_{2}$-guanosine $3^{\prime}, 5^{\prime}$-monophosphate ( +3 cGMP) was added to each well. Samples were incubated on ice for 30 minutes. Following centrifugation at $4^{\circ} \mathrm{C}$ for 5 minutes at $1000 \mathrm{~g}$ to pellet cell debris, the supernatant was transferred to a clean plate and the samples were analyzed for cGMP content by reversephase liquid chromatography-tandem mass spectrometry. cGMP concentrations were determined using a standard curve (Supplemental Fig. 1, A and B). Concentration-response data were fit using a fourparameter fit [log (agonist) vs. response - variable slope] with a 95\% CI using GraphPad Prism version 5. The $\mathrm{EC}_{50}$ was interpolated from the curve fit.

cGMP and Vasodilator-Stimulated Phosphoprotein (VASP) Phosphorylation. HEK-293 cells expressing GloSensor 40F cGMP (Promega, Madison, WI) were maintained in Dulbecco's modified of Eagle's medium (Corning, Corning, NY) supplemented with $10 \%$ fetal bovine serum (HycloneThermoFisher Scientific, Waltham, MA) and $200 \mu \mathrm{g} / \mathrm{ml}$ hygromycin (Invitrogen, Carlsbad, CA). Cells were plated in culture medium in a $100 \mu \mathrm{l}$ volume at a density of 50,000 cells/well in a poly-D-lysine-coated 96-well flat-bottom plate (BD, Franklin Lakes, NJ). Cells were incubated overnight at $37^{\circ} \mathrm{C}$ in a humidified chamber with $5 \% \mathrm{CO}_{2}$. Medium was removed, and cells were washed twice with HBSS with calcium and magnesium. Cells were then incubated with $90 \mu \mathrm{l}$ of a solution containing $0.5 \mathrm{mM}$ IBMX in HBSS with calcium and magnesium for 15 minutes at $37^{\circ} \mathrm{C}$, followed by the addition of $10 \mu \mathrm{l}$ of $10 \times$ the indicated final concentration of IW-1973 (diluted from a $10 \mathrm{mM}$ dimethylsulfoxide stock) in the presence of varying concentrations of DETA-NONOate, and then incubated for an additional 20 minutes at $37^{\circ} \mathrm{C}$. For detection of cGMP formation, cells were lysed with $50 \mu \mathrm{l}$ per well of cGMP HTRF lysis buffer (Cisbio), and then assayed following the protocol of the HTRF cGMP assay kit (Cisbio). For detection of total VASP and phosphorylated VASP (pVASP) formation, cells were lysed with $50 \mu \mathrm{l}$ per well of HTRF lysis buffer (Cisbio), and then assayed following the protocol of the total VASP (Cisbio) and pVASP Ser239 (Cisbio) HTRF assay kits. All pVASP levels were normalized to total VASP, and data were normalized to the maximum response for cGMP and pVASP, respectively, determined with $1 \mu \mathrm{M}$ DETA-NONOate $+100 \mu \mathrm{M}$ IW-1973. Maximum cGMP and maximum pVASP were determined from a series of concentration responses of IW-1973 combined with varying levels of DETANONOate. Both cGMP and pVASP were found to plateau at the highest concentration of IW-1973 $(100 \mu \mathrm{M})+$ DETA-NONOate $(1 \mu \mathrm{M})$.

Pharmacokinetics. Male Sprague-Dawley rats (275-300 g; Harlan Laboratories, Indianapolis, IN) with indwelling jugular vein cannulae were fasted overnight prior to dosing. Animals were dosed either intravenously via bolus injection through a percutaneous catheter in the tail or orally via gavage. IW-1973 was formulated in $60 \%$ polyethylene glycol $400 / 40 \%$ water at $0.3 \mathrm{mg} / \mathrm{ml}(0.3 \mathrm{mg} / \mathrm{kg})$ for intravenous dosing and at $1 \mathrm{mg} / \mathrm{ml}(3 \mathrm{mg} / \mathrm{kg})$ in $100 \%$ polyethylene glycol 400 for oral dosing. Chow was returned to animals 4 hours postdose.

Blood from rats dosed via intravenous injection was collected at 15 time points ranging from 0.033 to 48 hours postdose. Blood from orally dosed rats was collected at 15 time points ranging from 0.25 to 48 hours postdose. Samples were collected into $\mathrm{K}_{2}$ EDTA separator tubes and processed to plasma by centrifugation (3500 rpm for 10 minutes). Plasma samples were prepared by protein precipitation and analyzed using liquid chromatography-tandem mass spectrometry.

Tissue Distribution. Wistar rats (male, 250-275 g, $n=6$; Harlan Laboratories) were administered IW-1973 at $10 \mathrm{mg} / \mathrm{kg}$ once a day for 5 days via oral gavage. IW- 1973 was formulated at $2 \mathrm{mg} / \mathrm{ml}(10 \mathrm{mg} / \mathrm{kg})$ in $0.5 \%$ (weight/volume) methylcellulose added to $1 \%$ hydroxypropyl methylcellulose with $0.2 \%$ Tween 80 in Milli-Q water. (Millipore Sigma, Burlington, MA) At 2 hours postdose on day 5, plasma was collected and animals were perfused with phosphate-buffered saline containing $1 \mathrm{mM}$ IBMX and $1 \mathrm{U} / \mathrm{ml}$ heparin. Liver, heart, kidney, and lung samples were collected and homogenized. Plasma and tissue samples were analyzed for IW-1973 levels using liquid chromatography-tandem mass spectrometry.

Human Vascular Tissue Relaxation. To determine the relaxation effect of IW-1973 on human blood vessels, human subcutaneous resistance arteries were obtained from three donors, females ages 27-51 undergoing elective surgeries. Arteries were mounted in myograph baths by means of a $40 \mu \mathrm{m}$ wire running through the lumen of the artery. Changes in tension were recorded using an isometric transducer (Danish Myo Technology A/S, Aarhus, Denmark). The arteries were precontracted with the thromboxane mimetic, U46619, at a final concentration of $100 \mathrm{nM}$. Upon stabilization of U46619 contractile response, a single addition of acetylcholine was made for a final concentration of $10 \mu \mathrm{M}$ to confirm functionality of the vascular endothelium including the presence of endogenous NO. Tissues that did not reach $\geq 50 \%$ relaxation in response to acetylcholine were excluded from the study. Tissues were then washed and contracted with U46619 at a final concentration of $100 \mathrm{nM}$, and an IW-1973 cumulative concentration-response curve $(0.1 \mathrm{nM}$ to $10 \mu \mathrm{M})$ was generated. At the end of the cumulative concentration-response curve, sodium nitroprusside was added for a final bath concentration of $100 \mu \mathrm{M}$ to determine maximal tissue relaxation response. IW-1973induced relaxation at each concentration was calculated as a percentage of the sodium nitroprusside-mediated maximum relaxation of U46619-induced contraction. A sigmoidal dose-response (variable slope) curve was fit with bottom values constrained to zero, and an $\mathrm{EC}_{50}$ value was estimated from this fitted curve using GraphPad Prism version 6.

Blood Pressure. The Dataquest A.R.T. acquisition and analysis system (Data Sciences International, St. Paul, MN) was used to monitor and analyze hemodynamic data from conscious, freely moving rats surgically implanted with a telemetry pressure transmitter (PAC40, Data Sciences International). Telemetry transmitter implantation was performed on rats under sterile conditions.

Briefly, spontaneously hypertensive rats (SHRs) (male, 230-250 g, 14 weeks of age; Charles River Laboratories, Wilmington, MA) and Wistar rats (male, 230-250 g, 12 weeks of age; Charles River Laboratories) were anesthetized with isoflurane and body temperature was maintained with a heating pad during surgery. A laparotomy was performed to expose the abdominal aorta. The catheter tip of the telemetry transmitter was inserted into the abdominal aorta and secured with a 5-0 silk suture (Ethicon, Inc., Somerville, NJ). The abdominal incision was closed with uninterrupted suture (4-0 silk; Ethicon, Inc.) and the body of the telemetry transmitter was placed in the abdominal cavity and secured to the abdominal wall. Approximately $100 \mu \mathrm{l}$ of $0.25 \%$ marcaine was applied directly to the closed abdominal wall, and the skin was then closed with suture (4-0 Vicryl 
absorbable; Ethicon, Inc.). Buprenorphine (0.05 mg/kg/d, s.c.) was administered immediately after the surgery for postoperative pain relief. After recovery from anesthesia, rats were returned to their home cages, placed on Data Sciences International receivers, and allowed a 5- to 14-day recovery period. IW-1973 was formulated in $0.5 \%$ (weight/volume) methylcellulose added to $1 \%$ hydroxypropyl methylcellulose with $0.2 \%$ Tween 80 in Milli-Q water at concentrations of $0.06,0.2,0.6$, and $2.0 \mathrm{mg} / \mathrm{ml}$. Each week, animals received a single concentration via oral gavage for 4 days followed by a 3-day washout period; the same group of animals received the next concentration the following week.

Maximum change from baseline of mean arterial pressure (MAP) was calculated using the 24-hour pre-first dose average subtracted from the lowest MAP value measured within 2 hours of dosing. Maximum change from baseline of heart rate (HR) was calculated using the 3-hour pre-first dose average subtracted from the 1-hour postdose average. Area over the curve was calculated using GraphPad Prism version 5. The data are expressed as mean \pm S.E.M. To determine the significant difference of the mean values across the independent strains, maximum change from baseline in MAP at day 3 , maximum change from baseline in HR at days 1 and 3, area over the curve at day 1 , and total area over the curve were analyzed by two-way analysis of variance (ANOVA), and significance was determined by Dunnett's post-hoc analysis. Statistical significance was indicated by a $P$ value of less than 0.05 . The average of 60 minutes of data derived from the real-time raw data was used for analysis.

Dahl Salt-Sensitive (DSS) Rat Model. Telemetry transmitter implantations and data monitoring, acquisition, and analysis were performed as described previously using DSS rats (male, 230-270 g; Harlan Laboratories). Normotensive control animals were maintained on $0.3 \% \mathrm{NaCl}$ [normal salt (NS)] diet for the 8-week study period. The vehicle control and treated animals were placed on $8 \% \mathrm{NaCl}$ [high-salt (HS)] diet for 2 weeks followed by 6 weeks of HS diet plus their respective treatments of vehicle, IW-1973 $(1,3$, or $10 \mathrm{mg} / \mathrm{kg} / \mathrm{d})$ or, as a reference control, losartan $(30 \mathrm{mg} / \mathrm{kg} / \mathrm{d}$ equivalent administered in water). IW-1973 was formulated at $8.3,25$, and $83 \mathrm{mg} / \mathrm{kg}$ standard chow with $8 \% \mathrm{NaCl}$ at Research Diets, Inc. (New Brunswick, NJ). At study end, animals were anesthetized with ketamine/xylazine $(75 / 10 \mathrm{mg} / \mathrm{kg}$, i.p.), and whole blood was collected for serum and plasma analyses. Following blood collection, the heart was perfused with heparin (1 U/ml of phosphate-buffered saline) containing $1 \mathrm{mM}$ IBMX. Kidneys and other organs were removed. Right and left kidneys were weighed separately, cut on the sagittal plane, and onehalf of each was snap frozen in liquid nitrogen and the other half was fixed with $10 \%$ neutral buffered formalin for histologic evaluation. At week 8, 24-hour urine samples were collected, centrifuged to remove debris, and stored at $-80^{\circ} \mathrm{C}$ until analysis. Serum samples were obtained at necropsy and stored at $-80^{\circ} \mathrm{C}$ until analysis. Urine and serum samples were analyzed using the Randox Daytona Clinical Chemistry Analyzer (Randox, Kearneysville, WV). All measurements were performed in accordance with the manufacturer's instructions.

For gene expression analysis, the left kidney was pulverized and powder $(5-10 \mathrm{mg}$ ) from the tissue was homogenized and processed using a QuantiGene sample processing kit in accordance with the manufacturer's instructions (Affymetrix, Fremont, CA). Gene expression in the tissue homogenates was measured using a QuantiGene 2.0 Plex Assay (Affymetrix/Life Technology, Santa Clara, CA) following the user's manual. Analytes were measured using Luminex MAGPIX (Bio-Rad, Hercules, CA). Median fluorescence intensity was generated for each gene target and normalized to the geometric mean expression of housekeeping genes (hprt1 and ppib), which were chosen to match the target transcript abundance.

MAP was averaged over each 24-hour period. Urinary protein was determined using urine protein and urine creatinine. Analyses of individual serum samples for interleukin 6 (IL-6) were conducted using a multiarray assay kit with a proinflammatory panel (Meso Scale Discovery, Gaithersburg, MD), and data were interpolated from standard curve values using GraphPad Prism version 6. To determine significant differences of mean values across multiple groups a oneway ANOVA was conducted, followed by Dunnett's multiple comparisons test versus the HS group. Statistical significance was indicated by a $P$ value of less than 0.05 .

Lipopolysaccharide (LPS)-Induced Inflammation Model. C57BL/6 mice (female, 8-13 weeks; Taconic, Hudson, NY) were weighed and assigned to groups to achieve similar average weights across groups. Animals were dosed with vehicle (by mouth), dexamethasone $(5 \mathrm{mg} / \mathrm{kg}$, i.p.), or IW-1973 (1 or $10 \mathrm{mg} / \mathrm{kg}$, by mouth). IW-1973 was formulated in $0.5 \%$ methylcellulose added to $1 \%$ hydroxypropyl methylcellulose with $0.2 \%$ Tween 80 in Milli-Q water and dosed at $5 \mathrm{ml} / \mathrm{kg}$.

One hour postdose, animals received $100 \mathrm{ng}$ of LPS in $0.2 \mathrm{ml}$ phosphate-buffered saline via intravenous injection. At 2 hours postLPS dose, mice were euthanized via $\mathrm{CO}_{2}$ inhalation and blood was collected via cardiac puncture. Serum was prepared and stored at $-80^{\circ} \mathrm{C}$. Cytokine levels were determined using cytometric bead array analysis kits (BD) in accordance with the manufacturer's protocol. A single analysis was performed for each sample. Data from cytometric bead array analysis kits were analyzed using flow cytometric analysis program array software. Data for individual samples were interpolated from standard curve values for each of the cytokines tested. Data were graphed and analyzed for statistical significance using GraphPad Prism, version 6. All data are expressed as mean \pm S.E.M. To account for variance between groups, significance was determined by one-way ANOVA followed by Fisher's least-squares difference test versus the vehicle group. Statistical significance was indicated by a $P$ value of less than 0.05 .

Unilateral Ureteral Obstruction (UUO) Model. UUO surgeries were performed on male Sprague-Dawley rats (male, 230-270 g; Harlan Laboratories) under sterile conditions. Briefly, animals were anesthetized with isoflurane and body temperature was maintained with a heating pad during surgery. The left kidney and ureter were exposed via a midline incision $(2$ to $3 \mathrm{~cm})$.

The ureter was ligated at two points proximal to kidney with 4-0 silk suture (Ethicon, Inc.). The ureter was then cut between the ligatures to prevent retrograde urinary tract infection. Rats in the control group underwent a sham laparotomy with ureteric manipulation through a midline incision. The abdominal incision was closed with uninterrupted suture (4-0 silk). Approximately $100 \mu \mathrm{l}$ of $0.25 \%$ marcaine was applied directly to the closed abdominal wall, and the skin was closed with a 4-0 Vicryl synthetic absorbable suture (Ethicon, Inc.). Longacting buprenorphine $(1.0 \mathrm{mg} / \mathrm{kg}$, s.c.) was given for pain relief. To achieve a dose level of $10 \mathrm{mg} / \mathrm{kg} / \mathrm{d}$, IW-1973 was formulated at $83 \mathrm{mg} / \mathrm{kg}$ in open standard diet chow (Research Diets Inc.). All treatments were initiated immediately after animals recovered from anesthesia. Body weights were obtained prior to surgery and at 1 and 2 weeks postsurgery. Plasma, serum, and 24 -hour urine samples were collected at 1 and 2 weeks postsurgery. At the end of the study, animals were euthanized with $\mathrm{CO}_{2}$ and the kidneys were removed. The right and left kidneys were weighed separately and cut sagittally, with one-half snap frozen in liquid nitrogen and one-half fixed with $10 \%$ neutral buffered formalin. Urine samples were collected over 24 hours at 1 and 2 weeks postsurgery. Urine samples were centrifuged to remove debris and stored at $-80^{\circ} \mathrm{C}$ until analysis. Whole blood was collected, and serum and plasma samples were prepared and stored at $-80^{\circ} \mathrm{C}$ until analysis.

The hydroxyproline content of the left kidney (obstructed) was assayed using the Hydroxyproline Assay Kit (Sigma-Aldrich). Briefly, $100 \mathrm{mg}$ tissue was homogenized in $1 \mathrm{ml}$ of water and transferred to a pressure-tight glass vial. $\mathrm{HCl}(37 \%)$ at a volume of $1 \mathrm{ml}$ was then added to the glass vial. The tissue samples were hydrolyzed at $120^{\circ} \mathrm{C}$ for 20 hours. Hydrolyzed samples and hydroxyproline standards (0-1.6 $\mu \mathrm{g} / \mathrm{well})$ were added to a 96 -well plate, $30 \mu \mathrm{l}$ per well. The 96 -well plate was placed in a $60^{\circ} \mathrm{C}$ oven until all wells were evaporated to dryness. A chloramine T/oxidation buffer mixture $(100 \mu \mathrm{l})$ was added to each sample and standard well, and the plate was incubated at room temperature for 20 minutes. Diluted 
p-dimethylaminobenzaldehyde (DMAB) reagent was then added at a volume of $100 \mu \mathrm{l}$ to each sample and standard well, and incubated at $60^{\circ} \mathrm{C}$ for 60 minutes. The absorbance was measured at $560 \mathrm{~nm}$.

Gene expression in the left kidney was measured according to the methods described previously for the DSS model. Median fluorescence intensity was generated for each gene target and normalized to the geometric mean expression of housekeeping genes (pol2ra and ppib), which were chosen to match the target transcript abundance. All data are expressed as mean \pm S.E.M. To determine the significant difference of the mean values across multiple groups a one-way ANOVA was conducted, followed by Dunnett's multiple comparisons test compared with the UUO control. Statistical significance was indicated by a $P$ value of less than 0.05 .

\section{Results}

IW-1973 is a sGC Stimulator that Enhances NO Signaling. IW-1973 is a sGC stimulator from a novel pyrazolopyrimidine heterocyclic structural class (Fig. 1A). IW-1973 stimulation of SGC as measured by cGMP production was determined using purified human recombinant $\alpha 1 \beta 1$ secondGC (Fig. 1B). At a concentration of $30 \mu \mathrm{M}$, IW-1973 alone increased cGMP 6 -fold from baseline to a mean of $303 \mathrm{nM}(95 \% \mathrm{CI}, 196-469, n=5)$. In the presence of the NO donor DETA-NONOate $(30 \mu \mathrm{M})$, IW-1973 stimulated a concentration-dependent increase in the production of cGMP [geometric mean of $\mathrm{EC}_{50} 267 \mathrm{nM}$ (eight separate experiments); 95\% CI, $152.1-467.9 \mathrm{nM}$ ], with $30 \mu \mathrm{M}$ raising cGMP levels to $3001 \mathrm{nM}(95 \% \mathrm{CI}, 2567-3510, n=5)$, a 10 -fold increase relative to $30 \mu \mathrm{M}$ IW-1973 without $\mathrm{NO}(n=5)$ and 60 -fold relative to baseline (without NO or IW-1973).

IW-1973 did not increase guanylate cyclase activity in heme-free sGC, generated through incubation of the recombinant enzyme with Tween 20. Furthermore, oxidation of sGC heme by treatment with $1 \mathrm{H}-[1,2,4]$ oxadiazolo[4,3,-a]quinoxalin1-one reduced IW-1973-stimulated activity by approximately $60 \%$ (Fig. 1C.) In contrast, the heme-independent sGC activator cinaciguat potently increased cGMP production under heme-free conditions (Fig. 1C).

The ability of IW-1973 to stimulate sGC and act in synergy with NO was further assessed in HEK-293 cells, which endogenously express sGC (Fig. 2A). In the absence of NO, IW-1973 stimulated a concentration-responsive increase in cGMP. With increasing concentrations of the NO donor DETANONOate, $30 \mu \mathrm{M}$ IW-1973 stimulated greater increases in cGMP production (96 nM cGMP for IW-1973 alone vs. $431 \mathrm{nM}$ cGMP for IW-1973 with $10 \mu \mathrm{M}$ DETA-NONOate), and progressively left shifted the IW-1973 concentration-response $\mathrm{EC}_{50}$ (by $>54$-fold with $10 \mu \mathrm{M}$ DETA-NONOate). In the presence of $10 \mu \mathrm{M}$ DETA-NONOate, IW-1973 stimulated sGC with an $\mathrm{EC}_{50}$ of $197 \mathrm{nM}$ (geometric mean of 11 independent experiments, 95\% CI of 94.4-411 nM).

A<smiles>OC(F)(F)C(F)(F)CNc1nc(-c2cc(-c3ccon3)n(Cc3ccccc3F)n2)ncc1F</smiles>

B

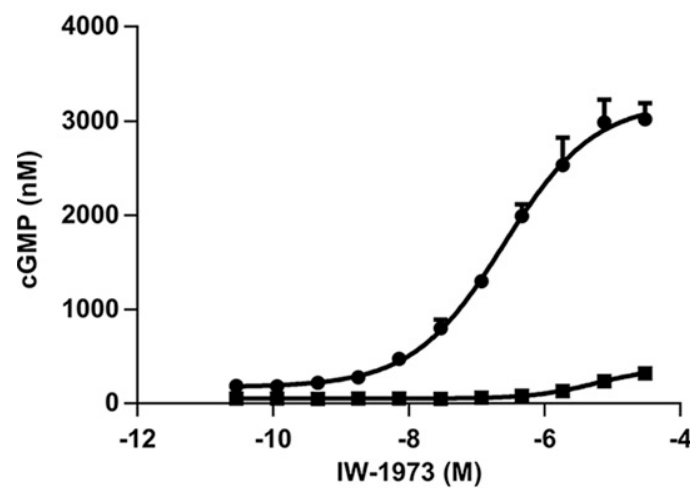

$\longrightarrow \quad 30$ 3M DETA-NONOate
C

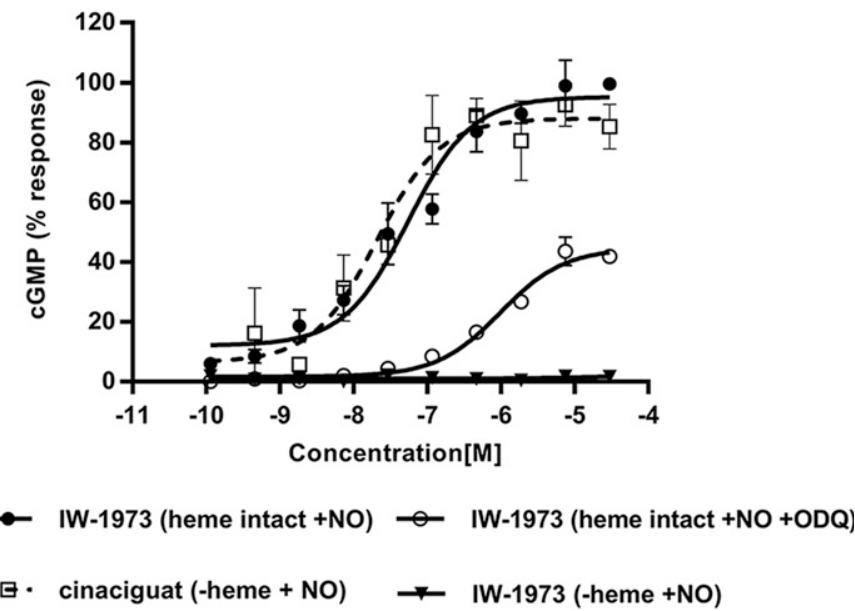

Fig. 1. (A) Chemical structure of IW-1973, a sGC stimulator from a novel pyrazolopyrimidine heterocyclic class of compounds. (B) Representative curve showing stimulation of human recombinant $\alpha 1 \beta 1 \mathrm{sGC}$ with IW-1973 in the absence and presence of the NO donor DETA-NONOate (30 $\mu \mathrm{M})$. Data are presented as mean + S.E.M., $n=5$ per group. (C) cGMP production of IW-1973 and cinaciguat using heme-dependent and independent sGC enzyme, data represent mean of $\%$ cGMP response \pm S.E.M., $n=3-5$. 
A

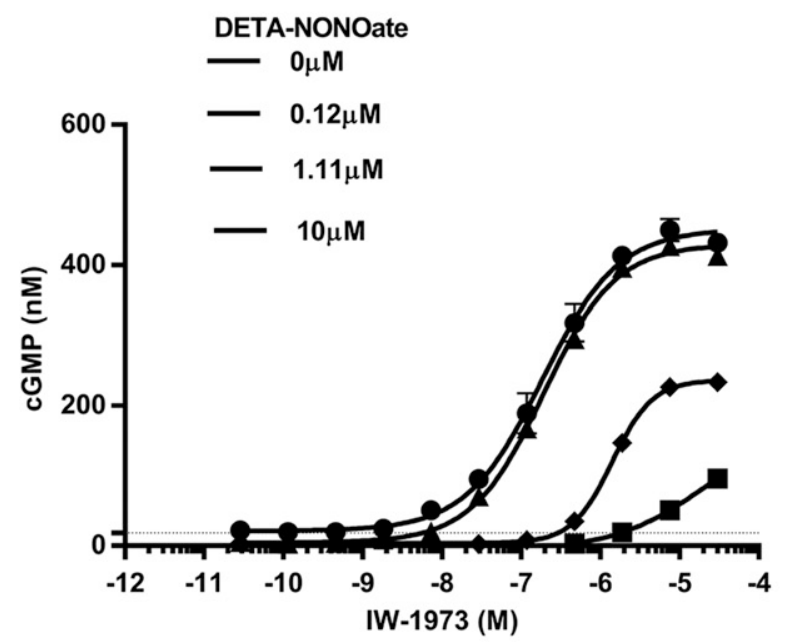

B

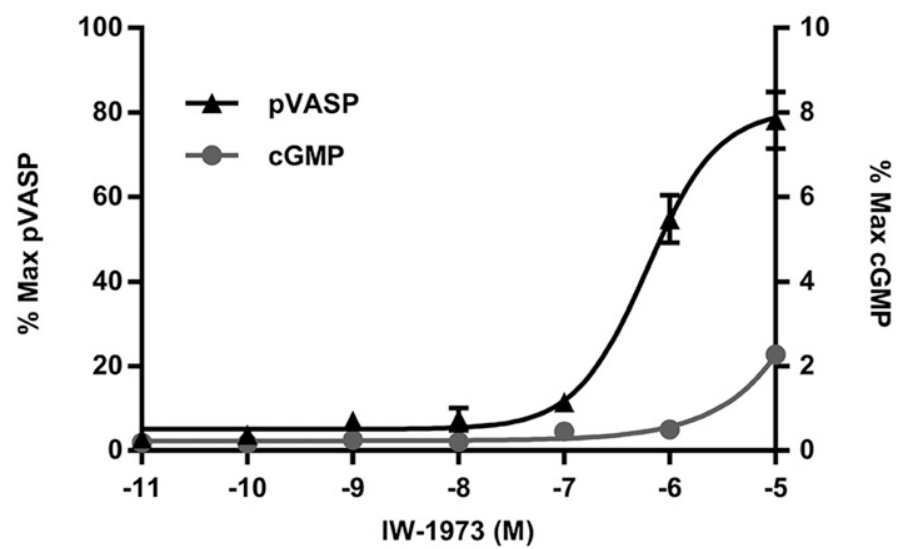

Fig. 2. (A) Stimulation of endogenous sGC in HEK-293 cells by IW-1973 (30 pM to $30 \mu \mathrm{M})$ in the absence of the NO donor DETA-NONOate and in the presence of varying concentrations of DETA-NONOate $(0.12-10 \mu \mathrm{M})$. Data are presented as mean \pm S.E.M., $n=2$ per group. (B) cGMP and pVASP concentration response relationship to IW-1973 (without DETA-NONOate) in HEK-293 GloSensor 40F cGMP cells. cGMP levels and pVASP(Ser239)/ VASP levels were determined by Cisbio HTRF assays. For plotted cGMP and pVASP, each data point represents three independent cellular assays.

NO-sGC-cGMP signaling induced by IW-1973 was further characterized in HEK-293-derived GloSensor 40F cGMP cells by monitoring phosphorylation of VASP, a target of protein kinase G. cGMP and pVASP were measured following treatment with IW-1973 alone and in combination with DETANONOate. The cGMP and pVASP response to IW-1973 (alone, no DETA-NONOate) is shown in Fig. 2B. Although both cGMP and pVASP demonstrated a concentration response to IW-1973, near-complete phosphorylation of VASP (78\%) was associated with effects on cGMP that were small (2\%) relative to the maximal cGMP effect (determined with $1 \mu \mathrm{M}$ DETANONOate $+100 \mu \mathrm{M}$ IW-1973, data not shown).

IW-1973 Pharmacokinetics and Tissue Distribution in Rats. The PK profile of IW-1973 was assessed in male Sprague-Dawley rats via intravenous (Fig. 3A) and oral routes (Fig. 3B). The median time to reach maximum concentration for IW-1973 was 8 hours with a $C_{\max }$ of $254 \mathrm{ng} / \mathrm{ml}$; the

A

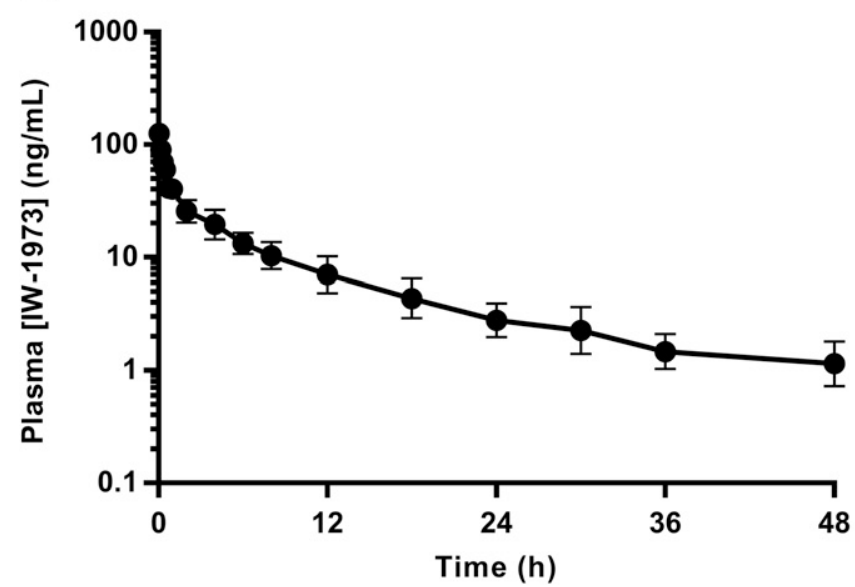

estimated oral half-life was 9.2 hours, with an estimated oral bioavailability of $102 \%$. Systemic clearance as determined from intravenous PK was $13.8 \mathrm{ml} / \mathrm{min} / \mathrm{kg}$ and the steady-state volume of distribution was $10.5 \mathrm{l} / \mathrm{kg}$.

Tissue distribution was assessed in the liver, heart, kidneys, and lungs of animals administered oral IW-1973 at $10 \mathrm{mg} / \mathrm{kg}$ once daily for 5 days. Tissue levels in the organs analyzed were greater than plasma levels, and the highest levels were observed in the liver (Table 1). These results were further verified by quantitative whole-body autoradiography (Banijamali et al., 2017).

IW-1973 Reduced Blood Pressure in Normotensive and Hypertensive Rats. The effect of IW-1973 on systemic hemodynamics was tested in vivo in telemetered normotensive and SHRs. When administered orally once daily for 4 days at doses of $0.3,1,3$, and $10 \mathrm{mg} / \mathrm{kg}$, IW-1973 invoked a dosedependent reduction in MAP that was sustained for 6 hours in

B

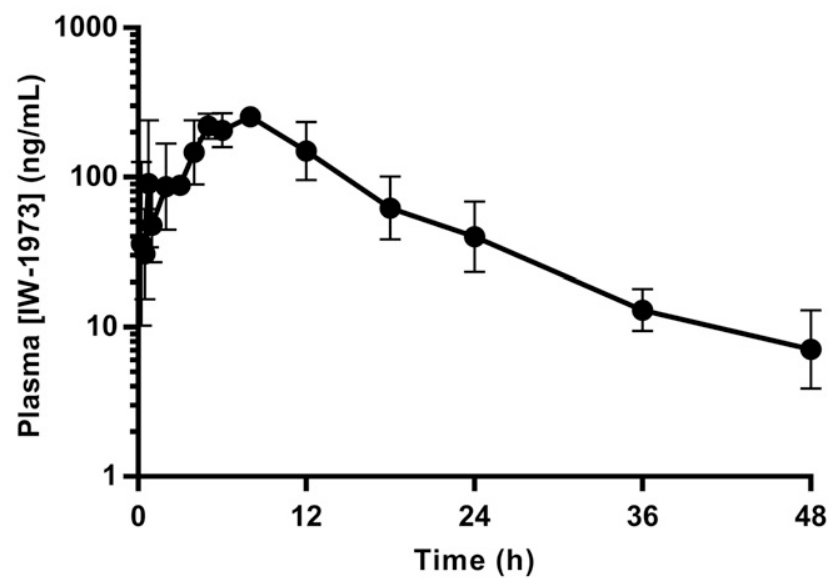

Fig. 3. Pharmacokinetic profile of IW-1973 in male Sprague-Dawley rats following single intravenous administration of IW-1973 [0.3 mg/kg in $60 \%$ polyethylene glycol (PEG) 400/40\% water] (A) and oral administration of IW-1973 (3 mg/kg in PEG 400) (B). Data are presented as mean $\pm 95 \%$ CI, $n=6$. 
TABLE 1

Tissue-to-plasma ratios of IW-1973

Tissue-to-plasma ratios (mean \pm S.E.M.) of IW-1973 were determined from whole organ analysis performed 2 hours after final dose in male Sprague-Dawley rats administered oral IW-1973 once daily for 5 days. Data are presented as tissue/plasma ratio \pm S.E.M., $n=6$.

\begin{tabular}{ccccc}
\hline IW-1973 & Liver & Heart & Kidney & Lung \\
\hline Tissue/plasma ratio & $19.9 \pm 1.3$ & $4.7 \pm 0.5$ & $5.9 \pm 2.0$ & $7.6 \pm 0.7$ \\
\hline
\end{tabular}

both normotensive (Fig. 4A) and hypertensive (Fig. 4B) rats. Maximum changes in MAP were observed between 2 and 6 hours after dosing. On day 3 of dosing, significant effects on maximum change from baseline in MAP were observed at the 1,3 , and $10 \mathrm{mg} / \mathrm{kg}$ doses in both normotensive $(n=6$ per group; $P \leq 0.01$ for all doses) and hypertensive rats $(n=6$ per group; $P \leq 0.01, P \leq 0.001$, and $P \leq 0.001$, respectively) compared with their respective vehicle controls (Fig. 4E).
Heart rate was significantly increased versus controls on day 3 at the $0.3,3$, and $10 \mathrm{mg} / \mathrm{kg}$ doses in normotensive $(P \leq 0.05$, $P \leq 0.01$, and $P \leq 0.05$, respectively) rats, and at the $10 \mathrm{mg} / \mathrm{kg}$ dose in hypertensive $(P \leq 0.05)$ rat (Fig. $4 \mathrm{~F})$. The maximum absolute change in MAP was greater in SHRs than in normotensive rats $(25.2 \pm 0.8 \mathrm{~mm} \mathrm{Hg}$ vs. $11.9 \pm 0.9 \mathrm{~mm} \mathrm{Hg}$ at $10 \mathrm{mg} / \mathrm{kg}$ on day 3 ), while the maximum absolute change in HR was less in SHRs compared with normotensive rats (71.4 $\pm 11.4 \mathrm{~mm} \mathrm{Hg}$ vs. $39.1 \pm 13.7 \mathrm{~mm} \mathrm{Hg}$ at $10 \mathrm{mg} / \mathrm{kg}$ on day 3$)$.

IW-1973 Relaxes Endothelium Intact Human Resistance Arteries. The mechanism for blood pressure reduction was explored with human vascular rings in vitro. IW-1973 effected a concentration-dependent relaxation of endothelium intact human subcutaneous resistance arteries precontracted with U-46619 (contractions ranging from 8 to $22 \mathrm{~g}$ ) with $\mathrm{EC}_{50}$ values ranging from 4.9 to $402.7 \mathrm{nM}$ and a maximum relaxation response of $93.2 \%-96.8 \%$ (Supplemental Fig. 2) as calculated from the sodium nitroprusside-mediated maximum
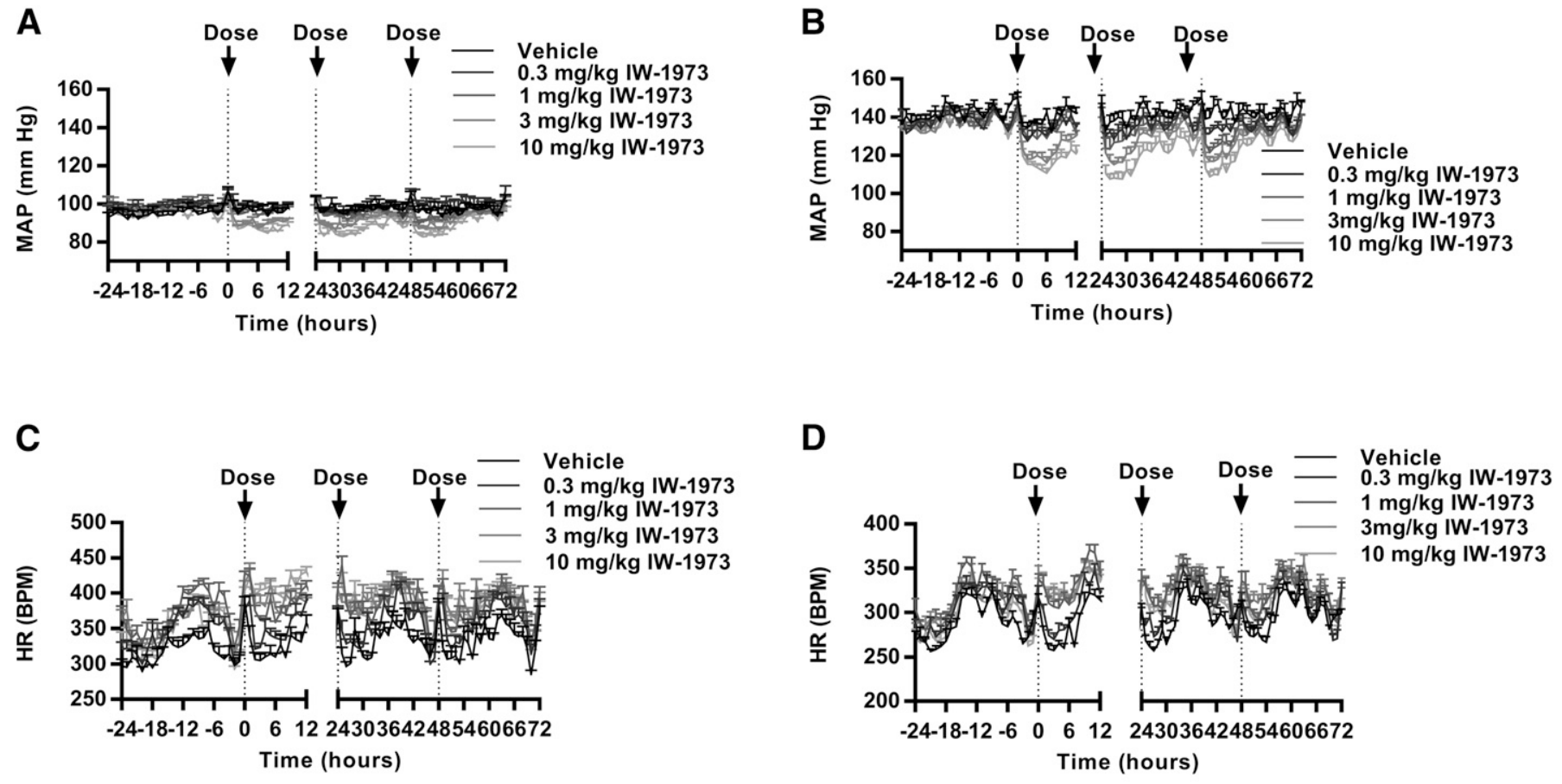

$\mathbf{E}$

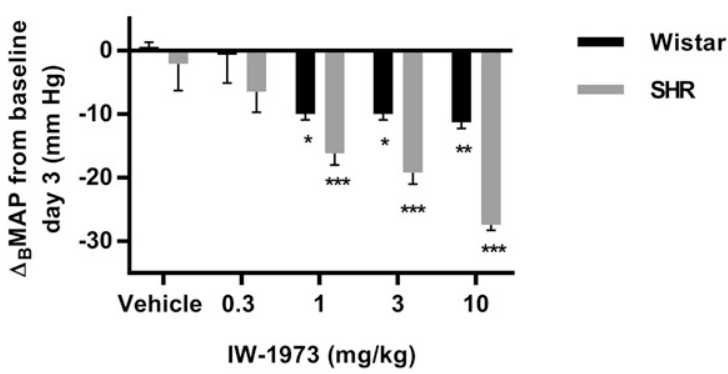

$\mathbf{F}$

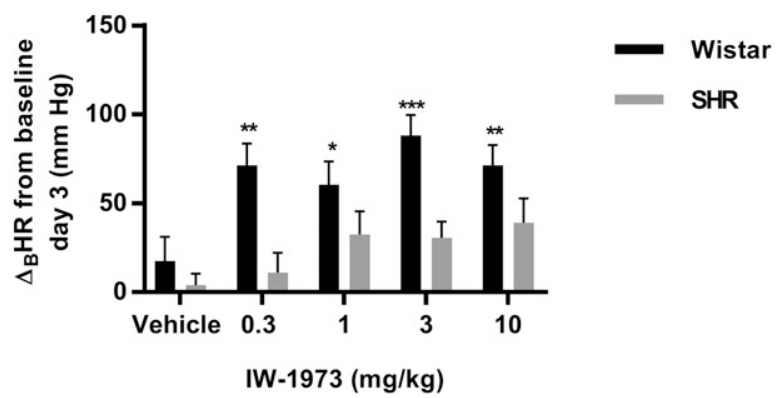

Fig. 4. MAP and HR in normotensive Wistar (A and C, respectively) and SHR (B and D, respectively) measured by telemetry for 1 day before dosing (baseline) and continuing for 3 days of once daily administration of vehicle or IW-1973 (0.3-10 mg/kg/d) by oral gavage for a total of 4 days. Data are plotted as mean + S.E.M. over time, $n=6$ per group. (E) Data from (A and B) are plotted as peak change from 24-hour baseline in MAP \pm S.E.M. following the day 3 dose (48-72 hours). (F) Data from (C and D) are plotted as peak change from 24-hour baseline in HR \pm S.E.M. following the day 3 dose. Significant changes in MAP and HR compared with the vehicle for the respective rat strains was determined by two-way ANOVA followed by Dunnett's post-test, $* P \leq 0.05 ; * * P \leq 0.01 ; * * P \leq 0.001$. 
relaxation that ranged from $97 \%$ to $99 \%$ for each of the tissues tested.

Chronic Effects of IW-1973 on Hemodynamics, Inflammation, Proteinuria, and Renal Fibrosis in the DSS Model. The DSS rat model of hypertension and heart failure (Geschka et al., 2011) was used to assess the effects of chronic IW-1973 treatment on body weight, hemodynamics, inflammation, proteinuria, and renal fibrosis. Animals on a HS diet had a lower rate of weight gain throughout the course of the study. There was no significant difference between the HS control group and IW-1973 or losartan-treated animals until the sixth and final week of treatment (Supplemental Fig. 3)

Prior to the start of treatment, MAP was higher in rats in the HS control group than in the NS group $(145.5 \pm 4.5 \mathrm{~mm} \mathrm{Hg}$ vs. $113.25 \pm 1.75 \mathrm{~mm} \mathrm{Hg})$. Treatment with IW-1973 induced a dose-dependent decrease in MAP that began during the first week of dosing and was sustained for the 6 weeks of treatment (Fig. 5). The effect of IW-1973 at $3 \mathrm{mg} / \mathrm{kg} / \mathrm{d}$ on MAP was comparable to the effect of losartan at $30 \mathrm{mg} / \mathrm{kg} / \mathrm{d}$ throughout the study. HR remained unchanged throughout the course of the study (Supplemental Fig. 4).

After 6 weeks of treatment with IW-1973 or controls, proinflammatory cytokines were assessed in the serum of all groups. Levels of serum IL-6 were significantly greater in animals in the HS vehicle group compared with animals on a NS diet (Fig. 6A). Compared with the HS vehicle group, rats treated with $10 \mathrm{mg} / \mathrm{kg} / \mathrm{d}$ IW-1973 had reduced levels of IL-6 ( $P \leq 0.01 \mathrm{vs.} \mathrm{HS} \mathrm{vehicle)} \mathrm{that} \mathrm{were} \mathrm{similar} \mathrm{to} \mathrm{IL-6} \mathrm{levels} \mathrm{in}$ animals on the NS diet as well as those receiving losartan at $30 \mathrm{mg} / \mathrm{kg} / \mathrm{d}$ ( $P \leq 0.05 \mathrm{vs}$. HS vehicle $)$.

Urinary protein was higher in animals receiving a HS diet than in those on a NS diet $(P \leq 0.001)$. Urinary protein was lower in both IW-1973-treated animals at $10 \mathrm{mg} / \mathrm{kg} / \mathrm{d}$ and losartan-treated animals at $30 \mathrm{mg} / \mathrm{kg} / \mathrm{d}$ than in $\mathrm{HS}$ vehicle animals $(P \leq 0.05)$ (Fig. 6B).
Renal gene expression of the fibrosis markers TGF $\beta 1$ and Col $1 \alpha 1$ were higher in the HS vehicle group relative to the NS group $(P \leq 0.001)$ and expression of these genes were lower in the kidneys of rats treated with 3 and $10 \mathrm{mg} / \mathrm{kg} / \mathrm{d} \mathrm{IW}-1973$ compared with the HS vehicle rats $(P \leq 0.001)$ as shown in Fig. 6 B. At $3 \mathrm{mg} / \mathrm{kg}$, IW-1973 was comparable to losartan, which significantly decreased the expression of both genes $(P \leq 0.001$ vs. HS).

Effect of IW-1973 in LPS-Induced Inflammation Model. To further characterize effects on inflammation, IW-1973 was assessed in an acute mouse model of LPSinduced inflammation. Dexamethasone $(5 \mathrm{mg} / \mathrm{kg})$ was used as a positive control. At the $10 \mathrm{mg} / \mathrm{kg} \mathrm{IW-1973} \mathrm{dose,} \mathrm{levels} \mathrm{of}$ proinflammatory cytokines IL-6 and TNF $\alpha$ were lower $(P \leq$ 0.01) compared with vehicle-treated mice. Levels of the anti-inflammatory cytokine interleukin 10 were increased, but not significantly, compared with vehicle (Fig. 7).

Effects of IW-1973 in a Rat UUO Model of Renal Fibrosis. The effects of IW-1973 were also examined in a nonhypertensive model of renal fibrosis. In this rat model, the ureter to the left kidney was ligated, resulting in fibrosis of the left kidney. In vehicle-treated rats, UUO increased renal levels of the collagen protein marker hydroxyproline $(P \leq$ $0.001)$ and Col $1 \alpha 1$ mRNA expression $(P \leq 0.001)$ and histopathological interstitial fibrosis $(P \leq 0.001)$. In rats treated with $10 \mathrm{mg} / \mathrm{kg} / \mathrm{d}$ IW-1973 for 14 days following UUO, increases in hydroxyproline protein levels $(P \leq 0.001)$ and col $1 \alpha 1$ mRNA expression $(P \leq 0.05)$ associated with UUO were attenuated (Fig. 8).

\section{Discussion}

IW-1973 is a clinical-stage small molecule sGC stimulator from a novel pyrazolopyrimidine heterocyclic structural class (Fig. 1). In vitro, IW-1973 demonstrated concentrationdependent stimulation of cGMP production by sGC in purified

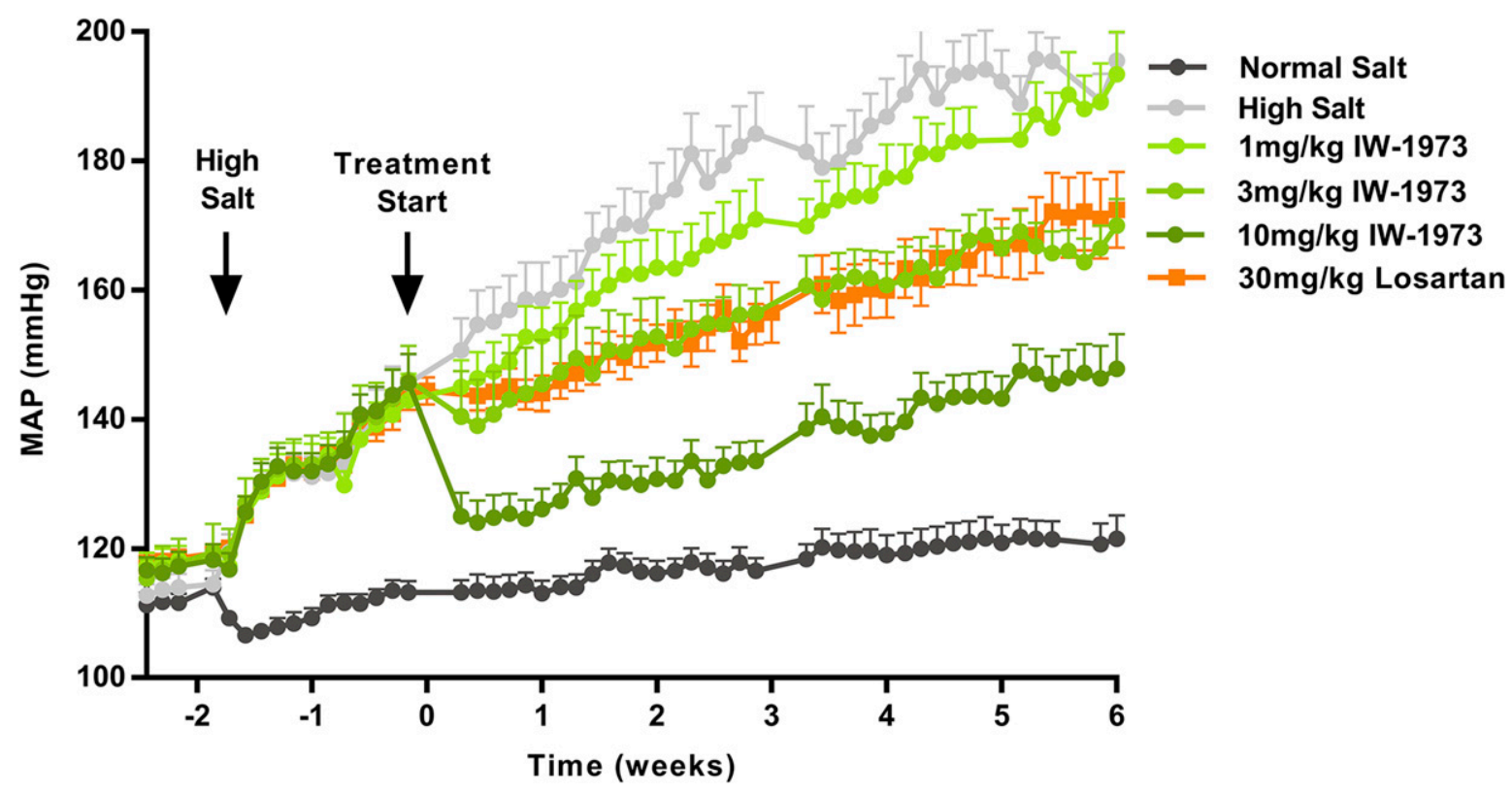

Fig. 5. MAP in DSS rats throughout 6 weeks of treatment with vehicle, IW-1973 (1, 3, and $10 \mathrm{mg} / \mathrm{kg}$, in chow), or losartan (30 mg/kg, in drinking water), shown as average MAP \pm S.E.M. (mm Hg), $n=8$ per group. Rats were provided NS or HS diet for 2 weeks before initiation of treatment and during treatment with vehicle, IW-1973, or losartan. Baseline measures were determined 1-3 days before initiation of treatment. 


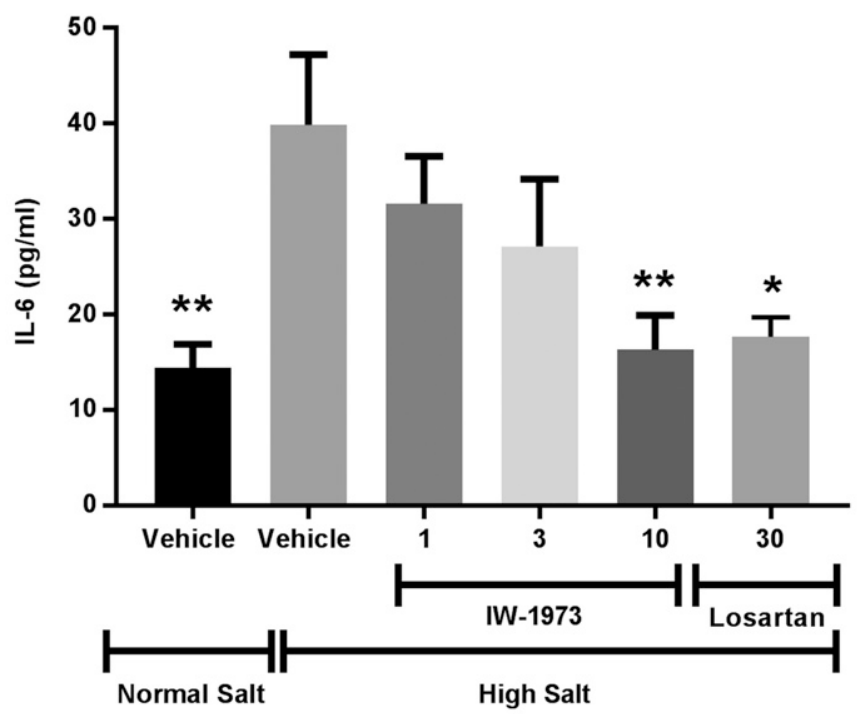

B
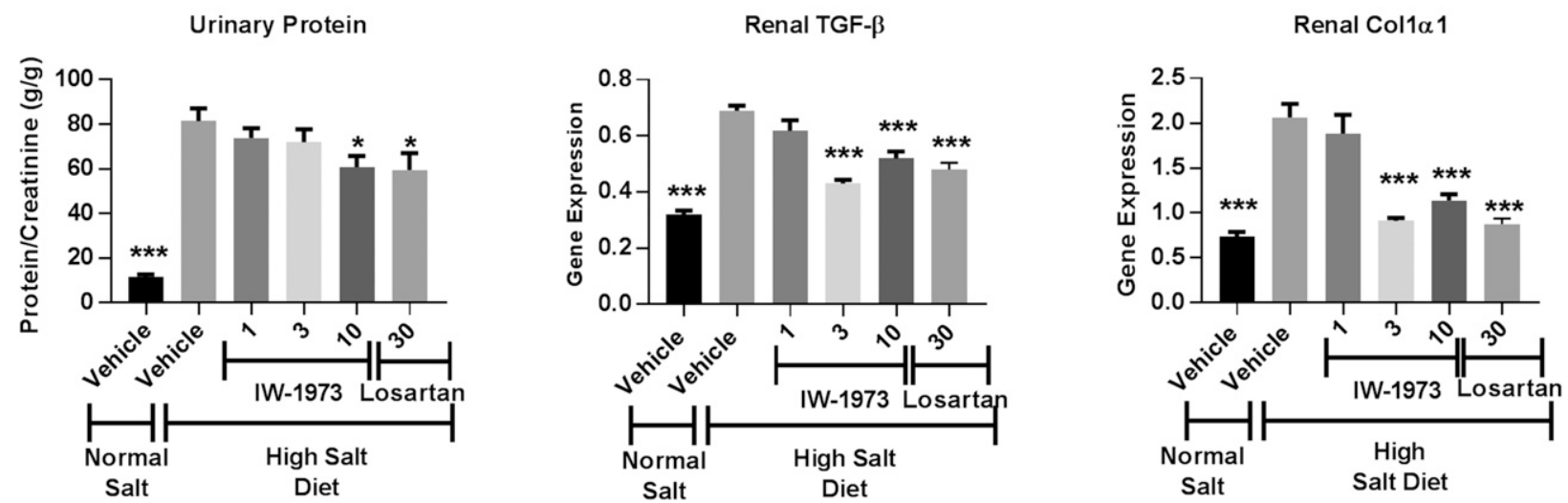

Fig. 6. Serum IL-6 (A) and urinary protein [protein (gram)/creatinine (gram)] and fibrotic gene expression (normalized to geometric mean of housekeeping genes hprt1, ppib) in kidneys (B) in the DSS rat model. All data are plotted as mean + S.E.M., $N=8 /$ group. All measures were taken after 6 weeks of treatment with IW-1973 or controls, significance relative to the HS vehicle group was determined by one-way ANOVA followed by Dunnett's post-test, $* P \leq 0.05 ; * * P \leq 0.01 ; * * * P \leq 0.001$.

enzyme and whole cell assays. Consistent with the definition of a sGC stimulator (Follmann et al., 2013), IW-1973 acted only on the reduced, heme-containing form of the enzyme, and demonstrated NO-independent stimulation of sGC and synergistic action with NO.

IW-1973 alone and in combination with a NO donor stimulated cGMP production in whole cells and triggered phosphorylation of VASP, a downstream target in the NO-sGC-cGMP-protein kinase G signaling pathway. Interestingly, comparatively low levels of sGC stimulation were sufficient to induce near-maximal pVASP levels. Ex vivo, IW-1973 relaxed human subcutaneous resistance arteries, demonstrating that IW-1973 can act in concert with endogenous NO to elicit smooth muscle relaxation in systems with a functional endothelium. Together, these results suggest that IW-1973 can act in systems with low and normal NO levels, and that downstream signaling pathways can be activated even at relatively low levels of sGC stimulation.
In vivo, NO-sGC-cGMP signaling plays a central role in regulating vascular tone. Orally administered IW-1973 reduced blood pressure in normotensive rats and in two rat models of hypertension (SHR and DSS); the magnitude of the blood pressure effect was greater in hypertensive rats than in normotensive rats. Robust and dose-dependent blood pressure reduction in the model of salt-sensitive hypertension, a disease associated with endothelial dysfunction and impaired NO signaling (Bragulat and de la Sierra, 2002; Hoffmann et al., 2015b), suggests that sGC stimulators will provide benefit in diseases with NO impairment. At a dose of $3 \mathrm{mg} / \mathrm{kg} / \mathrm{d}$ IW-1973 produced sustained blood pressure reduction over 6 weeks that was comparable to losartan over the same time period. These results suggest that, like losartan, IW-1973 has a durable effect on blood pressure that is not attenuated by the development of tolerance, which limits chronic use of NO donor drugs.

Several lines of evidence suggest that NO signaling through sGC plays a role in suppressing inflammation. For example, 
IL-6

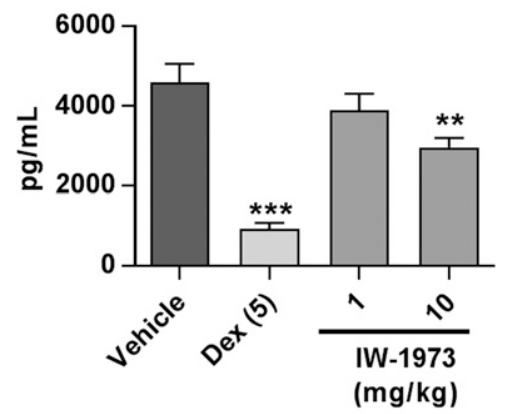

$\mathrm{TNF} \alpha$

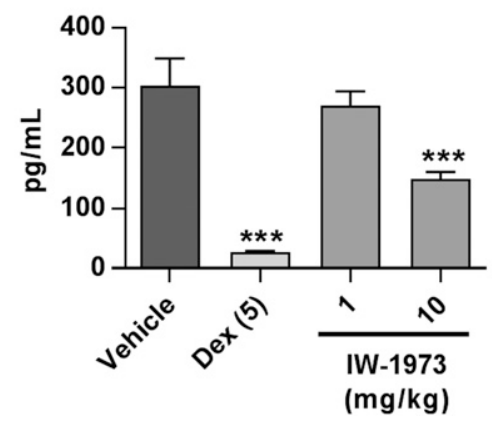

IL-10

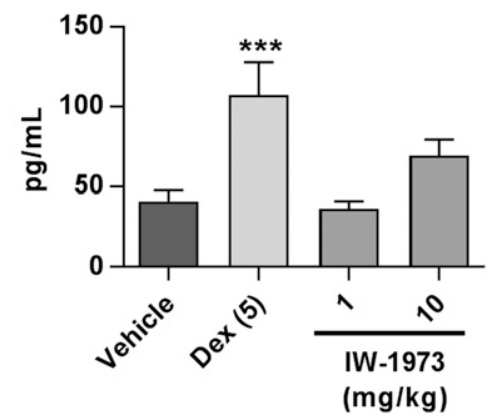

Fig. 7. Effect of IW-1973 on levels of the proinflammatory cytokines, IL-6 and TNF $\alpha$, and on the anti-inflammatory cytokine, interleukin 10 (IL-10). $\mathrm{C} 57 \mathrm{Bl} / 6$ male mice were dosed with vehicle, dexamethasone, or IW-1973 followed by LPS challenge to induce inflammation. Serum was collected 2 -hour postinduction, and samples were analyzed for cytokine concentrations. Data are presented as concentration (mean + S.E.M.) of cytokine in pg/ml, $n=$ 10 per group, significance was determined by one-way ANOVA followed by Fisher's least-square difference post-hoc analysis, compared with vehicle, $* P \leq 0.05 ; * * P \leq 0.01 ; * * * P \leq 0.001$.

leukocyte rolling and adhesion were increased 6-fold in $\mathrm{eNOS}^{-/-}$mice relative to wild-type controls, and both the sGC stimulator Bay 41-2272 and the NO donor DETA-NO restored leukocyte rolling and adhesion to wild-type levels (Ahluwalia et al., 2004). Furthermore, reduced NO has been shown to contribute to inflammation in adipose tissue in models of induced obesity (Handa et al., 2011). In the DSS model, IW-1973 treatment reduced serum levels of the proinflammatory cytokine IL-6. This finding, which is consistent with anti-inflammatory effects reported for sGC agonists in the DSS model (Geschka et al., 2011; Hoffmann et al., 2015b), prompted us to explore anti-inflammatory effects of IW-1973 in the LPS model, an acute inflammation model in normotensive mice. In this model, IW-1973 significantly reduced the proinflammatory cytokines IL- 6 and $\mathrm{TNF} \alpha$, and although not significant, increased the anti-inflammatory cytokine interleukin 10. Our findings in the LPS model add to mounting evidence (Ahluwalia et al., 2004; Handa et al., 2011; Glynos et al., 2015) that sGC stimulators like IW-1973 have direct anti-inflammatory effects.

Consistent with other sGC agonists (Stasch et al., 2015), IW-1973 showed renoprotective effects in kidney disease models of different etiologies. In the DSS rat model, orally administered IW-1973 reduced proteinuria and renal expression of the profibrotic cytokine TGF $\beta$ and $\operatorname{Col} 1 \alpha 1$, the major component of type I collagen. Renal histologic studies in the DSS model revealed renoprotective effects of IW-1973 at doses as low as $1 \mathrm{mg} / \mathrm{kg}$, including effects on glomerulosclerosis, interstitial fibrosis, interstitial inflammation, and tubular damage (Shea et al., 2015). The renoprotective effects of IW-1973 were also explored in the UUO model of renal fibrosis. Compared with vehicle-treated animals, IW-1973treated animals had significantly reduced kidney levels of Col $1 \alpha 1$ gene expression and hydroxyproline. These results are consistent with antifibrotic effects reported for other sGC agonists as well as for other effectors of the cGMP pathway in the kidney and other organs (Sandner and Stasch, 2017). In addition to IW-1973's effects in the kidney, we have recently shown that IW-1973 has anti-inflammatory and antifibrotic activity in the liver in a model of nonalcoholic steatohepatitis at doses that do not affect blood pressure (Flores-Costa et al., 2018).

IW-1973 exhibited a PK profile in the rat that includes high oral bioavailability $(>90 \%)$, a large volume of distribution, and
Hydroxyproline

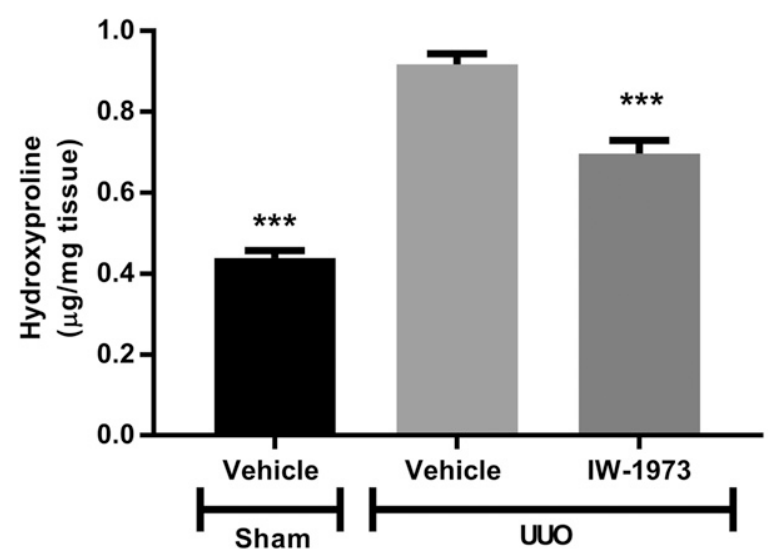

Col1 $\alpha 1$

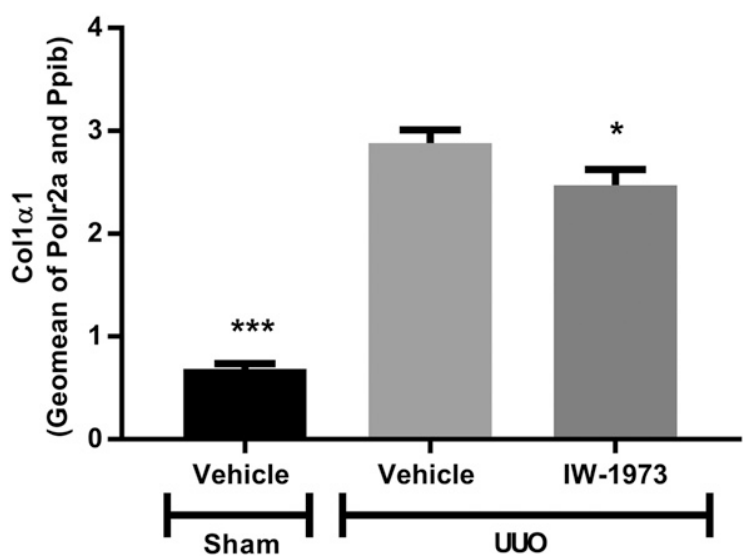

Fig. 8. Effects of IW-1973 (10 mg/kg/d in chow) on renal markers of fibrosis in the rat UUO model. Hydroxyproline levels (mean + S.E.M., $n=8)$ are reported as micrograms per milliliter of tissue, and Col1 $\alpha 1$ mRNA expression data are reported as ratio of Col1 11 to the housekeeping genes polr2a and ppib. Significance relative to vehicle control UUO animals was determined by one-way ANOVA followed by Dunnett's post-test, $* P \leq 0.05 ; * * * P \leq 0.001$. 
moderate clearance. Clinical studies suggest that predictions of once daily dosing from preclinical models translate to humans (Hanrahan et al., 2017). Mass balance studies performed in rats revealed that IW-1973 was primarily cleared by the liver (Zimmer et al., 2017). IW-1973 extensively distributed to tissues, with high levels observed in the liver, kidney, heart, and lung relative to the vascular compartment. A whole-body autoradiography study in rats also revealed high levels of IW-1973 in adipose tissue and skeletal muscle (Banijamali et al., 2017). The differential in large tissue distribution coupled with the high protein binding of IW-1973 leads to increased extravascular tissue access and sGC stimulation while plasma levels remain at low levels. The potential clinical significance of higher levels of compound in target tissues like liver and kidney may be to maximize the extravascular effects on inflammation and fibrosis relative to vascular, blood pressure effects.

Reduced NO signaling resulting from increased generation of reactive oxygen species, endothelial damage, and/or NO synthase impairment can lead to endothelial dysfunction, fibrosis, and/or inflammation. sGC stimulators are a relatively new class of NO-sGC-cGMP pathway modulators. Because
sGC stimulators bind directly to sGC to amplify NO signaling and increase local cGMP production, they offer a unique opportunity to treat hemodynamic dysregulation, inflammation, and fibrosis by restoring physiologic function (Fig. 9). We have shown that IW-1973 can positively impact each of these pathologies in animal models. The capacity of IW-1973 to restore normal hemodynamic function, and suppress inflammation and fibrosis suggests that its pharmacologic utility may not be limited only to diseases associated with reduced NO signaling, but that it has potential for treating or preventing diseases independent of NO. Indeed, the extensive tissue distribution of IW-1973 may afford an opportunity to exert pharmacological effects on inflammatory cells such as macrophages, neutrophils, and lymphocytes, profibrotic fibroblasts, and hepatic stellate cells, in target organs including the kidney.

In summary, IW-1973 is an orally active sGC stimulator that reduces blood pressure and exhibits antifibrotic, antiinflammatory, and renoprotective effects in animal models of hypertension, inflammation, and kidney disease. These animal models suggest that the extensive distribution of IW-1973 to tissues may allow for beneficial effects on organ fibrosis,
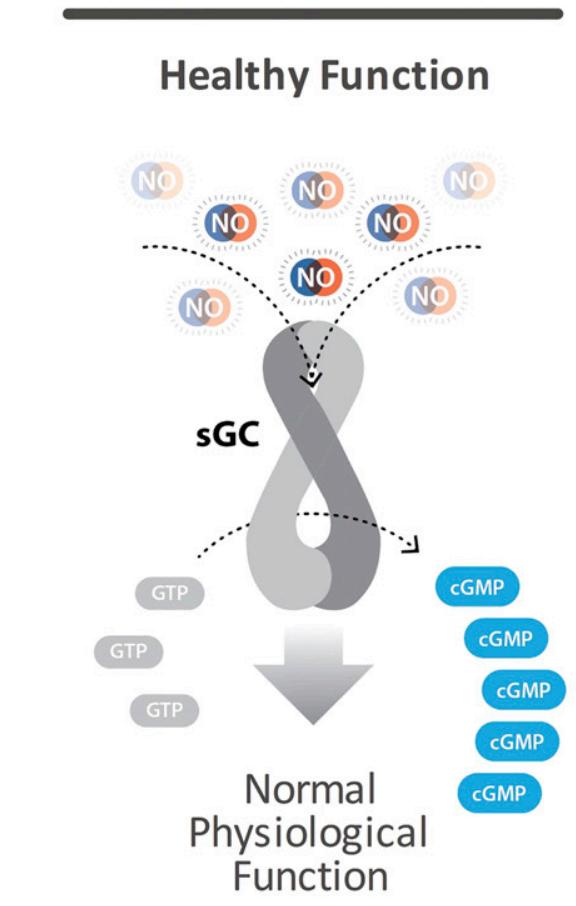

\section{Endothelial Dysfunction/ Reduced NO}

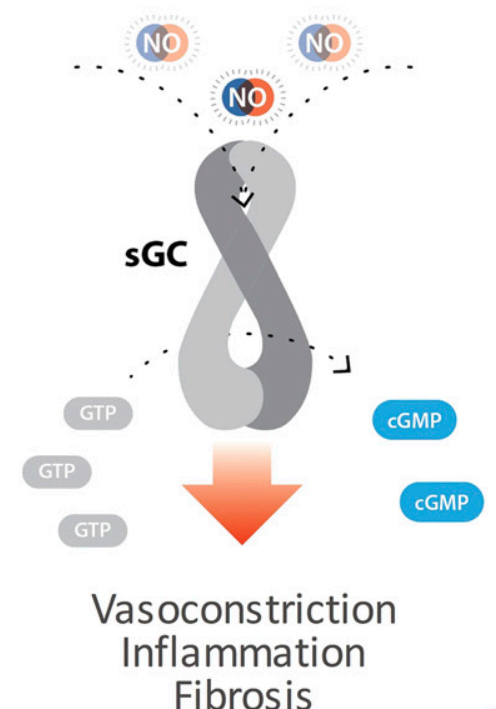

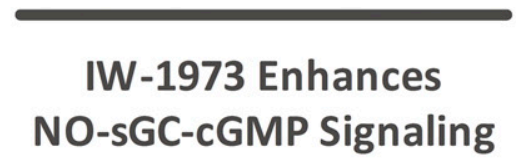

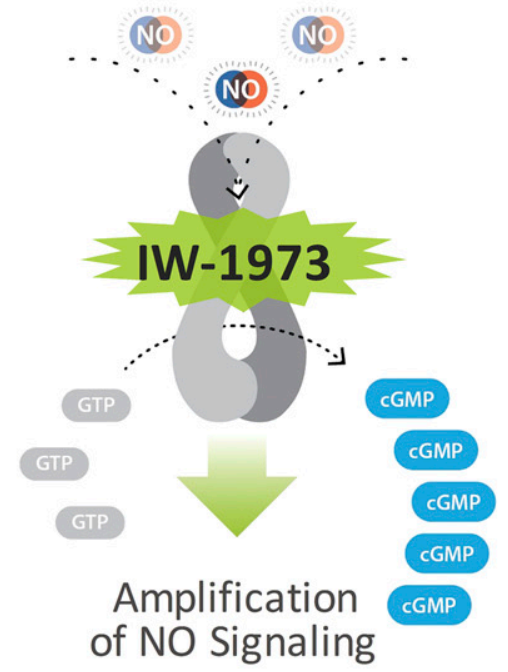

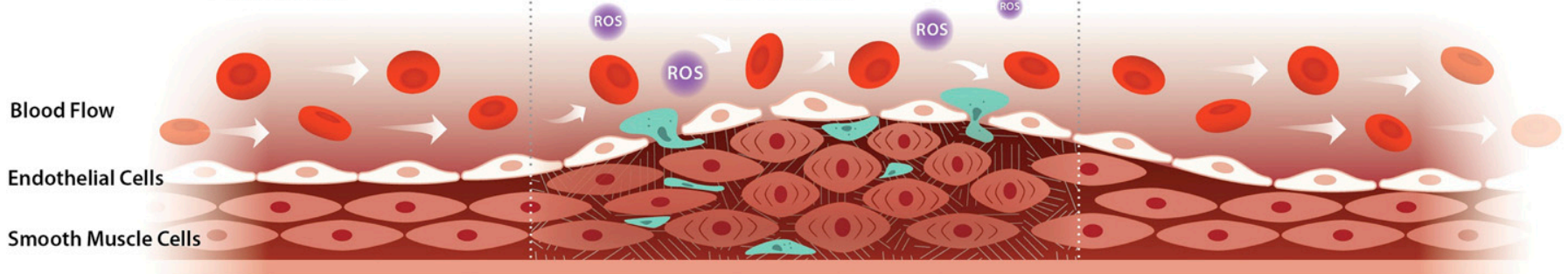

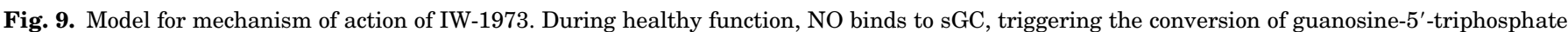

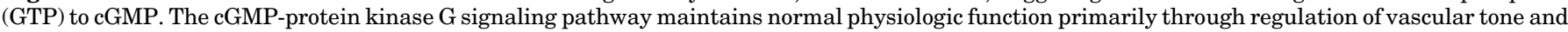

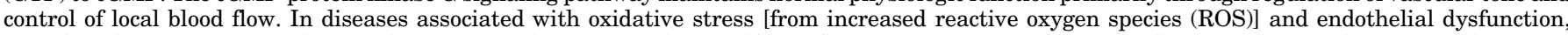

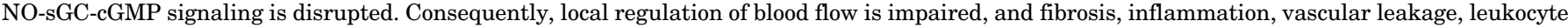

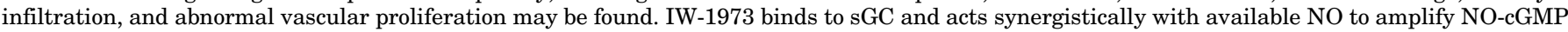

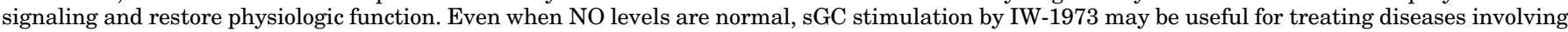
reduced peripheral blood flow, inflammation, and/or fibrosis. 
inflammation, and function at doses associated with little to no effects on blood pressure. IW-1973 has high oral bioavailability and a long PK half-life, which translated into PK consistent with once daily dosing in humans. Indeed, in a phase 1 study in healthy volunteers, once daily dosing of IW-1973 elicited not only dose-related increases in plasma cGMP but also reductions in blood pressure that were sustained through 24 hours postdose (Hanrahan et al., 2017). Clinical studies will be required to determine whether the ability of IW-1973 to enhance NO-sGC-cGMP signaling offers the potential to treat diseases associated with impaired NO signaling as well as diseases involving inflammation and fibrosis. The preclinical pharmacology of IW-1973 supports clinical studies in patients with diabetes and hypertension and its current clinical investigation for treatment of heart failure with preserved ejection fraction and diabetic nephropathy.

\section{Authorship Contributions}

Participated in research design: Zimmer, Tang, Profy, Milne, Currie, Masferrer.

Conducted experiments: Tobin, Shea, Germano, Bernier, Liu, Long, Miyashiro, Ranganath, Jacobson, Sykes, Wakefield, Sarno, Banijamali.

Contributed new reagents or analytic tools: Im, Sheppeck, Moore.

Performed data analysis: Tobin, Zimmer, Shea, Germano, Bernier,

Liu, Long, Miyashiro, Ranganath, Jacobson, Sykes, Wakefield, Sarno, Banijamali.

Wrote or contributed to the writing of the manuscript: Tobin, Zimmer, Shea, Germano, Bernier, Liu, Miyashiro, Jacobson, Sykes, Wakefield, Sarno, Banijamali, Profy, Milne, Masferrer.

\section{References}

Ahluwalia A, Foster P, Scotland RS, McLean PG, Mathur A, Perretti M, Moncada S, and Hobbs AJ (2004) Anti-inflammatory activity of soluble guanylate cyclase: cGMP-dependent down-regulation of P-selectin expression and leukocyte recruitment. Proc Natl Acad Sci USA 101:1386-1391.

Baliga RS, Zhao L, Madhani M, Lopez-Torondel B, Visintin C, Selwood D, Wilkins MR, MacAllister RJ, and Hobbs AJ (2008) Synergy between natriuretic peptides and phosphodiesterase 5 inhibitors ameliorates pulmonary arterial hypertension. Am J Respir Crit Care Med 178:861-869.

Banijamali A, Wakefield J, Barden T, Carvalho A, Zimmer DR, Currie M, Masferrer J, and Ribadeneira M. (2017) Quantitative tissue distribution and pharmacokinetics of IW-1973, a novel clinical-stage sGC stimulator, after oral administration in rats. Faseb $J \mathbf{3 1}$ (Suppl 1):666.7.

Bragulat E and de la Sierra A (2002) Salt intake, endothelial dysfunction, and saltsensitive hypertension. J Clin Hypertens (Greenwich) 4:41-46.

Budworth J, Meillerais S, Charles I, and Powell K (1999) Tissue distribution of the human soluble guanylate cyclases. Biochem Biophys Res Commun 263:696-701.

Conole D and Scott LJ (2013) Riociguat: first global approval. Drugs 73:1967-1975.

Derbyshire ER and Marletta MA (2012) Structure and regulation of soluble guanylate cyclase. Annu Rev Biochem 81:533-559.

Erdmann E, Semigran MJ, Nieminen MS, Gheorghiade M, Agrawal R, Mitrovic V, and Mebazaa A (2013) Cinaciguat, a soluble guanylate cyclase activator, unloads the heart but also causes hypotension in acute decompensated heart failure. Eur Heart $J$ 34:57-67.

Flores-Costa R, Alcaraz-Quiles J, Titos E, López-Vicario C, Casulleras M, DuranGüell M, Rius B, Diaz A, Hall K, Shea C, et al. (2018) The soluble guanylate cyclase stimulator IW-1973 prevents inflammation and fibrosis in experimental nonalcoholic steatohepatitis. Br J Pharmacol 175:953-967.

Follmann M, Griebenow N, Hahn MG, Hartung I, Mais FJ, Mittendorf J, Schäfer M Schirok H, Stasch JP, Stoll F, et al. (2013) The chemistry and biology of soluble guanylate cyclase stimulators and activators. Angew Chem Int Ed Engl 52: 9442-9462.

Geschka S, Kretschmer A, Sharkovska Y, Evgenov OV, Lawrenz B, Hucke A, Hocher B, and Stasch JP (2011) Soluble guanylate cyclase stimulation prevents fibrotic tissue remodeling and improves survival in salt-sensitive Dahl rats. PLoS One 6: e21853.

Gheorghiade M, Marti CN, Sabbah HN, Roessig L, Greene SJ, Böhm M, Burnett JC, Campia U, Cleland JG, Collins SP, et al.; Academic Research Team in Heart Failure (ART-HF) (2013) Soluble guanylate cyclase: a potential therapeutic target for heart failure. Heart Fail Rev 18:123-134.

Glynos C, Toumpanakis D, Loverdos K, Karavana V, Zhou Z, Magkou C, Dettoraki M, Perlikos F, Pavlidou A, Kotsikoris V, et al. (2015) Guanylyl cyclase activation reverses resistive breathing-induced lung injury and inflammation. Am J Respir Cell Mol Biol 52:762-771.

Handa P, Tateya S, Rizzo NO, Cheng AM, Morgan-Stevenson V, Han CY, Clowes AW, Daum G, O'Brien KD, Schwartz MW, et al. (2011) Reduced vascular nitric oxide-cGMP signaling contributes to adipose tissue inflammation during high-fat feeding. Arterioscler Thromb Vasc Biol 31:2827-2835.

Hanrahan JP, Wakefield J, Wilson P, Mihova M, Chickering JG, Ruff D, Hall M, Milne GT, Currie MG, and Profy AT (2017) Multiple-ascending-dose study of IW-1973, a soluble guanylate cyclase stimulator, in Proceeding of the AHA Council on Hypertension, AHA Council on Kidney in Cardiovascular Disease, American Society of Hypertension Joint Scientific Sessions; 2017 September 14-17; San Francisco, CA. Hypertension, September 2017

Hoffmann LS, Etzrodt J, Willkomm L, Sanyal A, Scheja L, Fischer AW, Stasch JP Bloch W, Friebe A, Heeren J, et al. (2015a) Stimulation of soluble guanyly cyclase protects against obesity by recruiting brown adipose tissue. Nat Commun 6:7235.

Hoffmann LS, Kretschmer A, Lawrenz B, Hocher B, and Stasch JP (2015b) Chronic activation of heme free guanylate cyclase leads to renal protection in Dahl saltsensitive rats. PLoS One 10:e 0145048.

Hrometz SL and Shields KM (2006) Sildenafil citrate for the treatment of pulmonary hypertension. Drugs Today (Barc) 42:771-784.

Ko FN, Wu CC, Kuo SC, Lee FY, and Teng CM (1994) YC-1, a novel activator of platelet guanylate cyclase. Blood 84:4226-4233.

Moncada S and Higgs EA (2006) Nitric oxide and the vascular endothelium. Handb Exp Pharmacol 176:213-254.

Münzel T, Sinning C, Post F, Warnholtz A, and Schulz E (2008) Pathophysiology, diagnosis and prognostic implications of endothelial dysfunction. Ann Med 40: $180-196$.

Murrell W (1879) Nitroglycerin as a remedy for angina pectoris. Lancet 1:80.

Sandner P and Stasch JP. (2017) Anti-fibrotic effects of soluble guanylate cyclase stimulators and activators: a review of the preclinical evidence. Respir Med 122 (Suppl 1):S1-S9

Shea C, Ranganath S, Liu G, Wachtel D, Germano P, Tobin J, Rivers S, Im GY, Sheppeck J, Nakai T, et al. (2015) sGC stimulator efficacy: beyond blood pressure in Dahl-salt sensitive model of hypertension. Faseb $J$ 29:623.9.

Stasch JP, Alonso-Alija C, Apeler H, Dembowsky K, Feurer A, Minuth T, Perzborn E, Schramm M, and Straub A (2002) Pharmacological actions of a novel NO-independent guanylyl cyclase stimulator, BAY 41-8543: in vitro studies. $\mathrm{Br} J$ Pharmacol 135:333-343.

Stasch JP, Pacher P, and Evgenov OV (2011) Soluble guanylate cyclase as an emerging therapeutic target in cardiopulmonary disease. Circulation 123 2263-2273.

Stasch JP, Schlossmann J, and Hocher B (2015) Renal effects of soluble guanylate cyclase stimulators and activators: a review of the preclinical evidence. Curr Opin Pharmacol 21:95-104

Zimmer DP, Tobin J, Shea C, Sarno R, Long K, Jacobson S, Tang K, Germano P, Wakefield J, Im GY, et al. (2017) Cardiovascular actions and tissue distribution of IW-1973 - a clinical-stage soluble guanylate cyclase stimulator, in Proceeding of the 8th International Conference on cGMP; 2017 June 23; Bamberg, Germany Biomed Central.

Address correspondence to: Jenny Tobin, Ironwood Pharmaceuticals, 301 Binney Street, Cambridge, MA 02142. E-mail: jtobin@ironwoodpharma. com 